(c) American Dairy Science Association, 2006.

\title{
Acute Experimental Mastitis Is Not Causal Toward the Development of Energy-Related Metabolic Disorders in Early Postpartum Dairy Cows
}

\author{
M. R. Waldron, A. E. Kulick, A. W. Bell, and T. R. Overton ${ }^{2}$ \\ Department of Animal Science, Cornell University, Ithaca, NY 14853
}

\section{ABSTRACT}

Twenty Holstein cows in early lactation ( $7 \mathrm{~d}$ in milk) were administered $100 \mu \mathrm{g}$ of Escherichia coli lipopolysaccharide (LPS) dissolved in $10 \mathrm{~mL}$ of sterile $0.9 \%$ $\mathrm{NaCl}$ saline (treatment; TRT) or $10 \mathrm{~mL}$ of sterile saline (control) into both right mammary quarters to test the hypothesis that acute experimental mastitis would have negative impacts on aspects of energy metabolism that might lead to the development of metabolic disorders. A primed continuous intravenous infusion (14$\mu \mathrm{mol} / \mathrm{kg}$ of BW priming dose; $11.5-\mu \mathrm{mol} / \mathrm{kg}$ of BW per $\mathrm{h}$ continuous infusion) of 6,6-dideuterated glucose was used to determine pre- and posttreatment glucose kinetics using steady-state tracer methodologies. The LPS-treated cows displayed productive, clinical, and physiological signs of moderate to severe inflammation; control cows displayed no signs of immune activation. Pretreatment glucose rates of appearance $(\mathrm{Ra})$ into plasma were similar $(715$ and $662 \pm 33 \mathrm{mmol} / \mathrm{h}$ for TRT and control, respectively) between treatment groups. Intramammary LPS infusion into TRT cows resulted in increased glucose Ra relative to control cows (mean glucose Ra from 150 through 270 min after intramammary infusion were 815 and $674 \pm 21 \mathrm{mmol} / \mathrm{h}$ for TRT and control cows, respectively). Furthermore, plasma concentrations of glucose increased, whereas plasma nonesterified fatty acids, glycerol, and $\beta$-hydroxybutyrate concentrations decreased, in TRT relative to control cows. Interestingly, plasma insulin concentration increased dramatically in TRT cows and occurred prior to the small increase in plasma glucose concentration. Although these results only represent the early stages of inflammation, they are not consistent with a causal relationship between mastitis and energy-related met-

Received June 6, 2005.

Accepted August 24, 2005

${ }^{1}$ Supported in part by the Cornell University Agricultural Experiment Station federal formula funds, Project No. 127453 received from Cooperative State Research, Education, and Extension Service, U.S. Department of Agriculture. Any opinions, findings, conclusions, or recommendations expressed in this publication are those of the authors and do not necessarily reflect the view of the U.S. Department of Agriculture.

${ }^{2}$ Corresponding author: tro2@cornell.edu abolic disorders and instead suggest a coordinated protective effect by the immune system on metabolism during the early stages of mammary insult.

Key words: mastitis, glucose, metabolism, energy

\section{INTRODUCTION}

The periparturient dairy cow undergoes a period of reduced immunological capacity for 2 to $3 \mathrm{wk}$ before and after calving (Mallard et al., 1998). Grommers et al. (1989) reported that fewer mammary quarters responded to low-dose Escherichia coli endotoxin during early lactation than during midlactation and that maximum cell count also occurred somewhat later and was less pronounced during early lactation than during midlactation. Furthermore, periparturient cows experienced more rapid bacterial growth, higher peak bacterial concentration, higher fever, and equal or greater proinflammatory cytokine concentrations in foremilk than did midlactation cows (Shuster et al., 1996). This increased susceptibility to infectious disease can have costly consequences, as total milk loss from a single case of clinical mastitis over the entire lactation ranged from 110 to $552 \mathrm{~kg}$ (Rajala-Schultz et al., 1999). It is not surprising then that mastitis was an important risk factor for culling throughout lactation (Grohn et al., 1998)

In addition to these direct costs of mastitis, cows that contract mastitis often experience other problems that detract from farm profitability. Curtis et al. (1985) reported that cows with either mastitis or metabolic disorders were $>9$ times as likely to become afflicted with the other adverse health events. This does not necessarily mean that one disorder causes the other; it may simply indicate that the environmental and physiologic conditions that predispose the cow to one disorder also predispose the cow to the other disorder.

A significant body of research has examined the effects of nutrition and metabolism on immune function. As an example, Lacetera et al. (2005) reported that aspects of lipid metabolism may compromise immune function because in vitro-stimulated peripheral blood mononuclear cells from overconditioned periparturient cows secreted less IgM and IFN- $\gamma$ than did mononuclear cells from thin cows. Furthermore, the hyperketonemia 
that is common during early lactation is reported to have multiple negative effects on several aspects of immunocompetence (Suriyasathaporn et al., 2000). Aspects of immune activation that affect milk synthetic physiology have also received significant attention (Shuster et al., 1991, 1995; Shuster and Harmon, 1992). However, the potential causal-mechanistic relationship between mastitis and metabolic disease has received little attention. Research utilizing midlactation dairy cows (Waldron et al., 2003), nonlactating heifers (Steiger et al., 1999), and sheep (Naylor and Kronfeld, 1985) reported phases of inflammatory plasma hyperglycemia followed by hypoglycemia; the latter phase was perhaps the result of decreased hepatic glucose release. Furthermore, Steiger et al. (1999) reported transient increased plasma NEFA concentration following intravenous LPS infusion into heifers, and Kushibiki et al. (2003) reported increased plasma NEFA concentrations in lactating cows intravenously administered bovine recombinant tumor necrosis factor- $\alpha$ (TNF- $\alpha$ ). Decreased plasma glucose concentration (perhaps with a concomitant decrease in hepatic glucose release) and elevated plasma NEFA during inflammation in the periparturient cow might be consistent with the etiology of energy-related metabolic disorders. Therefore, we hypothesized that immune activation of early lactation dairy cows using an experimental mastitis model would result in quantitative changes in energy metabolism that would be causal toward the development of the fatty liver-ketosis complex.

\section{MATERIALS AND METHODS}

\section{Cows and Diets}

Twenty Holstein cows from the Cornell University Dairy Teaching and Research Center that were entering second or greater lactation were used in this experiment. The Cornell University Institutional Animal Care and Use Committee approved all procedures involving animals. Cows were monitored for body condition, feed intake, and health status for several weeks prior to calving to ensure that uniform, healthy cows were enrolled on this experiment. All cows were evaluated weekly by 2 individuals to determine BCS (Edmonson et al., 1989) from 3 wk before expected calving through 2 wk after calving. Cows assigned to the 2 treatments were fed common diets throughout the experiment, and the entire experimental duration was conducted with cows calving over a period of about 2 mo. To help control for variation caused by the effect of time across the experiment, the control cow for a specific LPS-infused cow was assigned and studied within $1 \mathrm{wk}$ of the treated cow, sufficient forage was reserved at the dairy facility prior to initiation of the
Table 1. Diet composition ${ }^{1}$ and nutrients supplied ${ }^{2}$ by prepartum and postpartum diets during the study of the effects of LPS-induced experimental mastitis on metabolism of dairy cows in early lactation

\begin{tabular}{lcc}
\hline Component & Prepartum & Postpartum \\
\hline DM, \% & 50.28 & 46.23 \\
CP, \% of DM & 15.16 & 17.85 \\
Soluble protein, \% of CP & 48.27 & 42.91 \\
Metabolizable protein, g/d & 1,144 & 1,932 \\
ADF, \% of DM & 26.86 & 22.09 \\
NDF, \% of DM & 41.91 & 32.86 \\
Lignin, \% of DM & 4.77 & 3.97 \\
NFC, \% of DM & 33.90 & 39.62 \\
Starch, \% of NFC & 17.72 & 26.18 \\
Crude fat, \% of DM & 3.40 & 4.51 \\
NE, Mcal/kg & 1.44 & 1.64 \\
Metabolizable energy, Mcal/d & 28.5 & 50.0 \\
Ash, \% of DM & 7.58 & 7.82 \\
Ca, \% of DM & 1.40 & 1.00 \\
P, \% of DM & 0.40 & 0.37 \\
Mg, \% of DM & 0.38 & 0.29 \\
K, \% of DM & 1.31 & 1.34 \\
\hline
\end{tabular}

${ }^{1}$ Composition determined by the analysis of individual feedstuffs multiplied by the percentage of each feedstuff in the diet.

${ }^{2}$ Metabolizable protein and energy supplied as predicted by the Cornell Net Carbohydrate and Protein System (Fox et al., 2004).

experiment such that large changes would not be made in the forage base of the diet during the experiment, and minimum and maximum temperatures at the environmentally controlled metabolism facility were monitored daily to ensure ambient conditions would not affect metabolism. Cows were confined to tie stalls beginning approximately $28 \mathrm{~d}$ prior to expected parturition and were fed a total mixed diet balanced to meet or exceed nutrient requirements for nonlactating cattle as recommended by the National Research Council (2001). The prepartum diet was composed of $37.8 \%$ corn silage, $10.0 \%$ alfalfa hay-crop silage, $13.1 \%$ grass hay, $5.7 \%$ wheat straw, 3.7\% high-moisture shelled corn, and $29.7 \%$ concentrate grain, vitamin, and mineral mix on a DM basis. All cows were released from tie stalls and were offered 30 to 120 min of exercise 3 times/wk during the prepartum period. At parturition, cows were switched to a total mixed diet formulated using the Cornell Net Carbohydrate and Protein System (CNCPS; Fox et al., 2004) according to NRC (2001) recommendations for dairy cattle in early lactation. The postcalving diet consisted of $18.7 \%$ standard corn silage, $10.1 \%$ brown midrib corn silage, $22.3 \%$ alfalfa haylage, $1.8 \%$ alfalfa hay, $3.7 \%$ grass hay, $1.7 \%$ wheat straw, $21.6 \%$ high-moisture shelled corn, and $20.1 \%$ concentrate grain, vitamin, and mineral mix on a DM basis. The pre- and postcalving diet specifications are shown in Table 1.

The results of feed analysis (Table 1) indicate that the diets fed were similar to the formulated diets for both the prepartum and postpartum periods. The pre- 
partum diet contained $66.6 \%$ forage feeds, $15.2 \% \mathrm{CP}$, $41.9 \% \mathrm{NDF}, 33.9 \% \mathrm{NFC}, 1.44 \mathrm{Mcal}$ of $\mathrm{NE}_{\mathrm{L}} / \mathrm{kg}, 1.4 \%$ calcium, and $1.31 \%$ potassium on a DM basis. The CNCPS-predicted (Fox et al., 2004) metabolizable protein and ME supplied by the prepartum diet were 1,144 $\mathrm{g}$ and $28.5 \mathrm{Mcal} / \mathrm{d}$, respectively. The postpartum diet contained $58.3 \%$ forage feeds, $17.9 \% \mathrm{CP}, 32.9 \% \mathrm{NDF}$, $39.6 \% \mathrm{NFC}, 1.64 \mathrm{Mcal}$ of $\mathrm{NE}_{\mathrm{L}} / \mathrm{kg}$, and $1.0 \%$ calcium on a DM basis. The 18.4-kg mean daily DMI prior to intramammary infusion was predicted to supply 1,932 $\mathrm{g}$ of metabolizable protein and 50.0 Mcal of ME/d.

\section{Infusate}

Tracer Infusions. The 6,6-dideuterated-glucose (D2-glucose) was obtained from Cambridge Isotope Laboratories, Inc. (Andover, MA) and was tested for sterility and pyrogenicity by the manufacturer. Infusates for the bolus and continuous D2-glucose infusions were prepared $1 \mathrm{~d}$ prior to the experimental day using aseptic technique, autoclave-sterilized glassware, utensils, and saline $(0.9 \% \mathrm{NaCl})$. The average of 3 postpartum BW measurements was used in the calculation of bolus and continuous D2-glucose infusates for each cow. Bolus infusates contained $14 \mu \mathrm{mol}$ of D2-glucose/kg of BW dissolved in $10 \mathrm{~mL}$ of sterile physiological saline $(0.9 \% \mathrm{NaCl})$. Infusates for the continuous infusion contained $11.5 \mu \mathrm{mol}$ of D2-glucose/kg of BW per h of infusate and were dissolved into a total volume of $500 \mathrm{~mL}$ using sterile $0.9 \% \mathrm{NaCl}$.

Intramammary Infusions. Sterile physiological $0.9 \% \mathrm{NaCl}$ was used for the saline treatment (control). For the LPS treatment, $25 \mathrm{mg}$ of LPS (E. coli 0111:B4; Sigma-Aldrich Chemical Co., St. Louis, MO) was dissolved in $500 \mathrm{~mL}$ of sterile $0.9 \% \mathrm{NaCl}$ solution to yield a stock solution concentration of $50 \mu \mathrm{g}$ of LPS $/ \mathrm{mL}$. This stock LPS solution was stored at $4^{\circ} \mathrm{C}$ for the duration of the experiment. One day prior to the experimental day, $5 \mathrm{~mL}$ of the LPS stock solution was added to 20 $\mathrm{mL}$ of sterile $0.9 \% \mathrm{NaCl}$ to create a $10-\mu \mathrm{g} \mathrm{LPS} / \mathrm{mL}$ infusate that was stored overnight at $4^{\circ} \mathrm{C}$.

\section{Experimental Protocol}

Cows were transported from the Cornell University Dairy Teaching and Research Farm to the Cornell University Large Animal Research and Teaching Unit at approximately $4 \mathrm{~d}$ postpartum. All experimental procedures were performed at this facility, and while there, cows were milked $2 \times$ daily ( 0700 and $1900 \mathrm{~h}$ ) and were fed $3 \times$ daily $(0630,1200$, and $1830 \mathrm{~h}$ ) except on the day of infusion as detailed subsequently. Milk weights were recorded, and individual quarter milk samples and a composite milk sample were taken at each milking.
Feed offered and refused was weighed at each feeding for the determination of daily feed intake. Feed intake of LPS-treated cows was measured every $2 \mathrm{~h}$ on experimental days for the 8-h period following intramammary infusion. On experimental days following intramammary infusion, saline-treated cows were individually pair-fed every $2 \mathrm{~h}$, and feed intake was measured (per kilogram of $\mathrm{BW}^{0.75}$ basis) with an LPS-infused cow such that the effects of LPS infusion would not be confounded with feed intake.

Body weights were measured postcalving on 3 different $d$ prior to the experimental day. On approximately d 6 postpartum, cows were fitted with bilateral jugular vein catheters, and the main experimental day occurred on approximately d 7 postpartum $(6.7 \pm 0.3$ and $6.9 \pm$ 0.3 for LPS- and saline-treated cows, respectively; $P>$ 0.2 ). One jugular catheter was used for blood sampling. All samples were 15-mL draws added to disposable test tubes containing Na-heparin for a final concentration of 30 units $/ \mathrm{mL}$ of Na-heparin and were maintained on ice until centrifuged at $2,060 \times \mathrm{g}, 15 \mathrm{~min}, 4^{\circ} \mathrm{C}$ to harvest plasma. The plasma was stored at $-20^{\circ} \mathrm{C}$ until analysis. The contralateral catheter was used for infusions. Catheters were filled with sterile $0.9 \% \mathrm{NaCl}$ containing 200 units/mL of Na-heparin for periods of catheter inactivity $>20 \mathrm{~min}$, whereas catheters used more frequently were filled with sterile $0.9 \% \mathrm{NaCl}$ containing 100 units/ $\mathrm{mL}$ of Na-heparin.

Infusion and Sampling Protocol. A summary timeline of the main experimental day of infusions and sampling is depicted in Figure 1. On the experimental day, a baseline (-240 min) blood sample was obtained via a jugular catheter at approximately $0830 \mathrm{~h}(\sim 1 \mathrm{~h}$ after the conclusion of milking). Following this blood sample, $14 \mu \mathrm{mol}$ of D2-glucose/kg of BW was administered via the infusion catheter in a bolus $(<10 \mathrm{~s})$ infusion. The D2-glucose was chased from the catheter with $10 \mathrm{~mL}$ of sterile saline. Other than the -240 -min (baseline) sample that immediately preceded the D2-glucose bolus, all other blood samples were timed starting at the beginning of the bolus infusion and are expressed relative to the time of intramammary treatment infusion (i.e., intramammary LPS or saline administration occurred immediately after the 0-min blood sampling). Following the bolus D2-glucose infusion, blood was sampled at 2-min intervals through $-220 \mathrm{~min}$ for the measurement of the plasma D2-glucose enrichment following the bolus infusion. These measurements were used for the calculation of the glucose rate constant for elimination, pool size, half-life, turnover time, mean residence time, and rate of appearance (Ra) during the pretreatment steady-state period. Immediately following the -210-min blood sampling, a continuous infusion of D2-glucose was initiated at an infusion rate of 40 


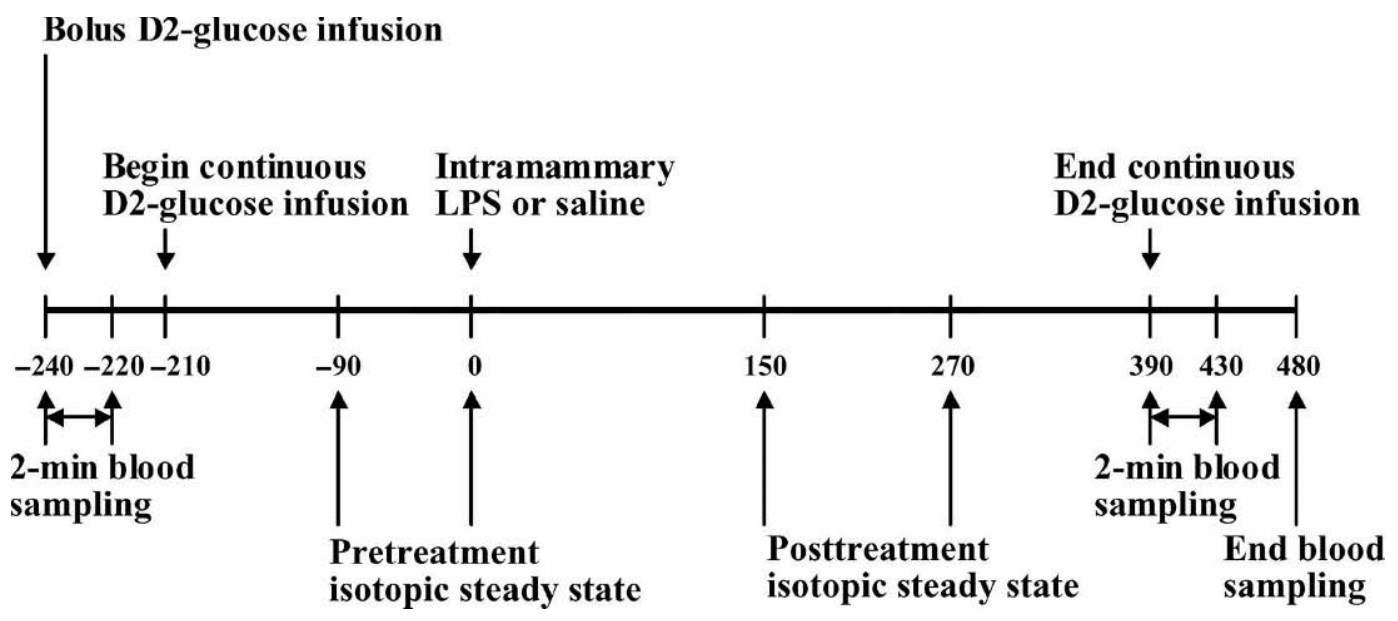

Figure 1. Experimental day timeline (min) for the study of the effects of LPS-induced experimental mastitis on metabolism of dairy cows during early lactation. Blood sampling was at 20- or 30-min intervals from -210 through 480 min, unless otherwise noted. D2-glucose = 6,6-dideuterated glucose.

$\mathrm{mL} / \mathrm{h}$ to deliver $11.5 \mu \mathrm{mol}$ of D2-glucose/kg of BW per $\mathrm{h}$ using a Plum XL infusion pump (Abbott Laboratories, North Chicago, IL) with a low-protein binding, 0.2- $\mu \mathrm{m}$ in-line sterile acrodisc filter (\#4192, Gelman Sciences, Ann Arbor, MI). This continuous D2-glucose infusion rate was maintained throughout the experimental day until $390 \mathrm{~min}$. Blood was sampled at 30-min intervals from -210 through $0 \mathrm{~min}$. Immediately after the 0 min blood sampling, intramammary treatments were administered. Either LPS $(100 \mu \mathrm{g})$ dissolved in $10 \mathrm{~mL}$ of sterile saline or sterile saline was administered into the teat canal of the 2 homolateral right mammary gland quarters using a 12-cc syringe tipped with an ethylene oxide-sterilized, J-12 teat infusion cannula (Jorgensen Laboratories, Inc., Loveland, CO). Teat ends were wiped thoroughly with sterile gauze moistened with $70 \%$ ethanol prior to cannula insertion. After infusion, mammary quarters were firmly massaged for 30 $\mathrm{s}$ to promote treatment dispersion throughout the infused quarters. Blood was sampled at 5-min intervals from 30 through $330 \mathrm{~min}$ and then at 20-min intervals through $390 \mathrm{~min}$. Data from the 5-min interval samples were intended to be used for modeling non-steady-state kinetics after intramammary infusions and are not reported in this paper; only data from 30- and 20-min intervals are included. The continuous D2-glucose infusion was terminated immediately following the 390min sampling, and blood was then sampled at 2-min intervals through $430 \mathrm{~min}$. Finally, blood was again sampled at 450 and $480 \mathrm{~min}$. Cows were milked immediately following the 480-min sampling time, creating an average milking interval of about $14 \mathrm{~h}$ between the morning and evening milkings on the experimental day. Subsequently, the interval between the evening milk- ing (experimental day) and the next morning milking was shortened to about $10 \mathrm{~h}$. As stated previously, all other milking intervals were $12 \mathrm{~h}$. Heart rate (as measured by auscultation) and rectal temperature were measured at -240-, -120-, at 30-min intervals from 0 through $480 \mathrm{~min}$ and at $20 \mathrm{~h}$ after the intramammary infusion.

\section{Analyses}

Milk. Milk samples were stored at $4^{\circ} \mathrm{C}$ with a preservative (Bronopol tablet, D\&F Control System, San Ramon, CA) and delivered daily to Dairy One Laboratories (Ithaca, NY) for compositional analysis. Composite milk samples were analyzed by infrared analysis (method 972.160; AOAC, 2000) for fat, true protein, lactose, and MUN. Milk SCC was analyzed by optical fluorescence (method 978.26; AOAC, 2000). Individual quarter samples were analyzed for SCC only.

Feed. Individual feed components of each diet were collected weekly and composited monthly throughout the study. A subsample of each weekly feed sample was dried at $55^{\circ} \mathrm{C}$ until static weight for measurement of DM content. Monthly feed composites were ground through a 2-mm screen on a Thomas-Wiley mill and were composited into a single sample for each feedstuff for the duration of the study. Weekly TMR samples were treated similarly, except that monthly composites were not composited into whole-study composites. These samples were analyzed on a monthly composite basis. Chemical analysis of all composite feed samples was performed by Dairy One Laboratories. The diet specifications reported are the result of individual feed 
ingredient analysis factored by the percentage of the diet occupied by that feedstuff.

Isotopic Analysis. Following removal from the freezer and thawing, plasma was first deproteinized using acetonitrile. Briefly, $250 \mu \mathrm{L}$ of acetonitrile was added to $100 \mu \mathrm{L}$ of plasma in a $1.5-\mathrm{mL}$ microcentrifuge tube. Plasma and acetonitrile were mixed using a vortex mixer and centrifuged at $8,000 \times g$ for $5 \mathrm{~min}$ in a Spectrafuge 16M microcentrifuge (National Labnet Co., Inc., Edison, NJ). The supernatant was aspirated and transferred to 7-mL glass screw-top scintillation vials (VWR International, West Chester, PA) and then dried in $37^{\circ} \mathrm{C}$ OA-SYS evaporator (Organomation Associates, Inc., Berlin, MA) under high-purity nitrogen gas ( 30 $\min )$. The scintillation vials were then capped and stored at ambient temperature $\left(25^{\circ} \mathrm{C}\right)$ until shipped for further analysis. Upon completion of deproteinization of all samples, samples were shipped to Metabolic Solutions, Inc. (Nashua, NH) for analysis of plasma glucose D2-glucose enrichment by gas chromatography-mass spectrometry (GC-MS).

Metabolites. Metabolite assays other than glycerol were conducted in 96-well microplates (Costar, Corning Inc., Acton, MA) and read using a microplate reader spectrophotometer (Molecular Devices, Sunnyvale, CA). These metabolites were analyzed by enzymatic colorimetric assays using procedures modified from available kits [glucose (glucose oxidase; kit 510-A) and BHBA (BHBA dehydrogenase; kit 310-UV), Sigma-Aldrich Co.; NEFA (NEFA-C, Wako Chemicals USA Inc., Dallas, TX)] and validated in our laboratory. Plasma glycerol concentration was determined fluorometrically from the reaction catalyzed by glycerol dehydrogenase using the method of Boobis and Maughan (1983) as modified by Sechen et al. (1990) and validated in our laboratory.

Hormones. Plasma insulin and cortisol concentrations were analyzed by radioimmunoassay (RIA) using commercially available kits validated in our laboratory from Linco Research, Inc. (St. Louis, MO) and Diagnostic Systems Laboratories, Inc. (Webster, TX), respectively. Intra- and interassay coefficients of variation for the insulin RIA were 5.2 and $15.4 \%$, and those for the cortisol RIA were 14.8 and $8.0 \%$, respectively.

\section{Calculations}

Enrichment. Calculation of plasma glucose enrichment with D2-glucose at each time point was performed by Metabolic Solutions, Inc. after GC-MS analysis. Briefly, a set of known standards composed of different concentrations of D2-glucose relative to unlabeled glucose was prepared and analyzed by GC-MS. The ratio of (mass +2$) /$ mass glucose fragments vs. mole fraction (moles of labeled glucose $\times$ moles of unlabeled glucose $^{-1}$ ) of D2-glucose was plotted to serve as the standard curve. Dried, deproteinized plasma samples were derivatized to the penta-acetate derivative using the procedure of Wolfe (1992) and subjected to GC-MS analysis. The ratios of (mass +2$)$ /mass glucose fragments were determined, and the percent mole fraction $\times 100$ was determined relative to the known standards. The -240-min percent mole fraction (natural basal enrichment of plasma glucose with dideuterated glucose) was subtracted from values for all other time points for each cow to yield the measure of enrichment, percent mole fraction excess [also called atom percent excess or mole percent excess (MPE)].

Kinetics. Glucose Ra was calculated as described by Wolfe (1992). Under steady-state conditions, the rate of appearance equals rate of disappearance; therefore, the more traditional terminology "flux rate" can be accurately used to describe the total Ra of the tracee (glucose). However, the use of the terminology "flux rate" is difficult to interpret when Ra does not equal rate of disappearance; therefore, its use has been discouraged (Wolfe, 1992). The Ra calculation used yields valid data during isotopic and physiologic steady-state conditions; therefore, conclusions are limited to periods of relative isotopic and tracee concentration equilibrium such as -90 through $0 \mathrm{~min}$ and 150 through $270 \mathrm{~min}$ in this study. The Ra was calculated by dividing the tracer (D2-glucose) infusion rate by plasma enrichment (MPE) at isotopic steady state and then subtracting the amount of tracer infused from the total Ra. This subtraction is necessary to correct for infused tracer mass, as stable isotope tracers must be infused at higher rates than radiolabeled tracers and, thus, cannot be considered massless.

Glucose kinetic calculations from the enrichment washout curve following the bolus D2-glucose infusion were determined using the methods of Wolfe (1992). The theoretical maximal plasma glucose enrichment with D2-glucose (if the entire bolus of glucose had been delivered simultaneously and was instantaneously mixed throughout the entire glucose pool) was determined by plotting plasma enrichment vs. the log time for each sample from 2 through $30 \mathrm{~min}$. The intercept of this line was used as the zero-time enrichment for subsequent kinetic calculations.

The rate constant for glucose elimination $(\mathrm{k})$ was determined by plotting the difference of the natural log of enrichment at time $t(\mathrm{Et})$ minus the natural log of enrichment at time zero (E0) vs. the negative of time $t$. The slope of the regression line through these points equals $[(\mathrm{LN}(\mathrm{Et})-\mathrm{LN}(\mathrm{E} 0)] /(-\mathrm{t})$, or $\mathrm{k}$.

Glucose pool size for each cow was determined by dividing the D2-glucose bolus dose $(14 \mu \mathrm{mol} / \mathrm{kg}$ of $\mathrm{BW})$ 
by the calculated plasma glucose peak enrichment (divided by 100 to account for the percentage decimals) at time zero. Glucose half-life was determined by calculating $\mathrm{LN}(2) / \mathrm{k}$. Glucose turnover time was calculated as $\mathrm{k}^{-1}$. In addition to the Ra calculation from plateau enrichment previously discussed, $\mathrm{Ra}(\mathrm{mmol} / \mathrm{h})$ was also calculated from the D2-glucose enrichment washout curve by multiplying pool size $\times \mathrm{k} \times 60$.

Statistics. The experiment was conducted as a completely randomized design with cow as the experimental unit. Data were analyzed by ANOVA as a mixed model with repeated measures using the mixed procedure of SAS (2001) with the repeated statement for assessment of the serial treatment and treatment $x$ time interaction effects (Littell et al., 1998). The repeated statement used time as the variable with cow within treatment as the subject and an autoregressive covariance structure. The variables in the model statement included covariate, treatment, time, and the interaction of treatment by time. Least squares means, appropriate standard errors, and treatment effects at specific time points for repeated measures analysis were generated using the LSMeans statement in conjunction with the pdiff option (SAS, 2001). Covariate analysis (using the pretreatment baseline values for each variable) was used for the assessment of all variables after LPS or saline treatment except for BCS, feed intake, milk production, milk components, heart rate, rectal temperature, and plasma glucose enrichment (when assessed across all time points) to help account for pretreatment cow-wise variation. Covariate was dropped from the model statement for variables not tested by covariate analysis. The average of values from -90 through 0 min (the period of pretreatment physiologic and isotopic steady state) for enrichment and $\mathrm{Ra}$ were used as the covariates for testing treatment and treatment by time interaction effects for these variables after intramammary infusion. The mean of the pretreatment baseline values for each variable from the 30 -min interval samples from -240 through 0 was used as the covariate for testing treatment and treatment by time interaction effects on plasma glucose, NEFA, BHBA, glycerol, and insulin concentrations. All reported means are the adjusted least squares means \pm standard error of the mean.

The area between the curves for the glucose Ra after LPS or saline infusion was determined using expand procedure of SAS with both cubic spline interpolation and the trapezoid rule (SAS, 2001). The analyzed area between the curves was generated using the least squares estimates for glucose $\mathrm{Ra}$ for each time point following intramammary infusion (0 to $390 \mathrm{~min}$ ).

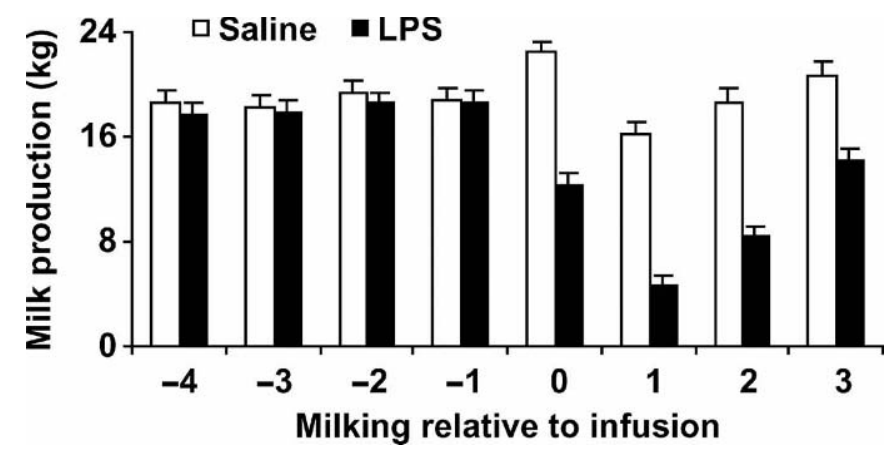

Figure 2. Milk production at each milking relative to the infusion of intramammary LPS or saline into dairy cows during early lactation. Error bars represent the standard error of the mean at each milking. **Treatment by time effect, $P<0.01$.

\section{RESULTS}

Body weights were not different between treatments (668 \pm 22 and $659 \pm 22 \mathrm{~kg}$ for LPS- and saline-treated cows, respectively; $P>0.20$ ). Furthermore, weekly mean BCS and treatment by time changes in BCS from wk $-2(3.34 \pm 0.12$ and $3.29 \pm 0.10$ for LPS- and salinetreated cows, respectively) to wk 1 ( $3.14 \pm 0.10$ and 3.19 \pm 0.10 for LPS- and saline-treated cows, respectively) relative to parturition were not different for cows assigned to either treatment $(P>0.20)$.

Milk yield at each milking for the $2 \mathrm{~d}$ before and after intramammary infusion is shown in Figure 2. The mean milk yield for the $2 \mathrm{~d}$ prior to treatment was $18.5 \mathrm{~kg}$ per milking and was not different between cows assigned to either treatment $(P>0.20)$. Following intramammary infusion, cows administered LPS had dramatically decreased milk yield $(P<0.01)$ relative to saline-treated controls during each of the subsequent 4 milkings. Despite a milking interval extended to $14 \mathrm{~h}$, the first milking after LPS infusion (milking $0 ; 8 \mathrm{~h}$ between intramammary infusion and milking time) displayed a $34 \%$ decrease in milk yield-a $45 \%$ decrease relative to control cows at the same milking with the same milking interval. The nadir in milk production occurred at the second milking after LPS infusion (Milking 1) when milk production was decreased by $72 \%$ relative to control cows. Milk production from successive milkings gradually recovered; however, milk production was still suppressed at the fourth milking after LPS administration $(P<0.01)$. Yields of milk fat, true protein, and lactose also dramatically decreased for several milkings after LPS administration ( $P<0.01$; data not shown). Milk SCC of homolateral udder halves (Figure 3) were significantly increased in the right udder halves of LPSinfused cows only. Using the linear score equation, the SCC for each of the 4 milkings following LPS treatment were sustained at a linear score of approximately 10 


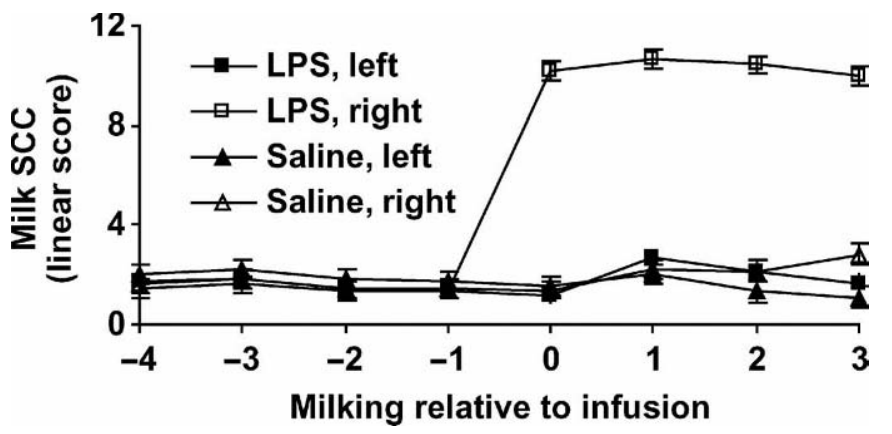

Figure 3. Udder-half milk SCC at each milking relative to the infusion of intramammary LPS or saline into the right udder half of dairy cows during early lactation. Data are linear scores $\left[\log _{2}(\mathrm{SCC} /\right.$ $100,000)+3]$. Error bars represent the standard error of the mean at each milking. ${ }^{* *}$ Treatment by time effect (LPS, right udder half different from all other treatments), $P<0.01$.

vs. a linear score of approximately 2 for non-infused udder halves and control cows.

Daily feed DMI was decreased by LPS infusion (Figure 4). Daily intake was decreased by $49 \%$ on the day of infusion, $19 \%$ at $1 \mathrm{~d}$ postinfusion, and was not different from saline-infused cows by the second day after intramammary infusion. Saline-infused cows were pair-fed with an individual LPS-infused cow for the 8-h period following treatment; therefore, there was no difference in feed intake for the 0-, 2-, 4-, or 6-h feedings (Figure 5). However, all cows were fed for ad libitum intake beginning at the 8 -h feeding, and saline-treated cows consumed 7-fold more feed (treatment by time effect, $P$ $<0.01$ ) during this period that lasted until $18 \mathrm{~h}$ postinfusion.

Clinical signs of inflammation were observed within about $2 \mathrm{~h}$ of LPS infusion. Rectal temperature of LPStreated cows was elevated at 120 min, peaked at 330 min, was still elevated at $480 \mathrm{~min}$, but was not different

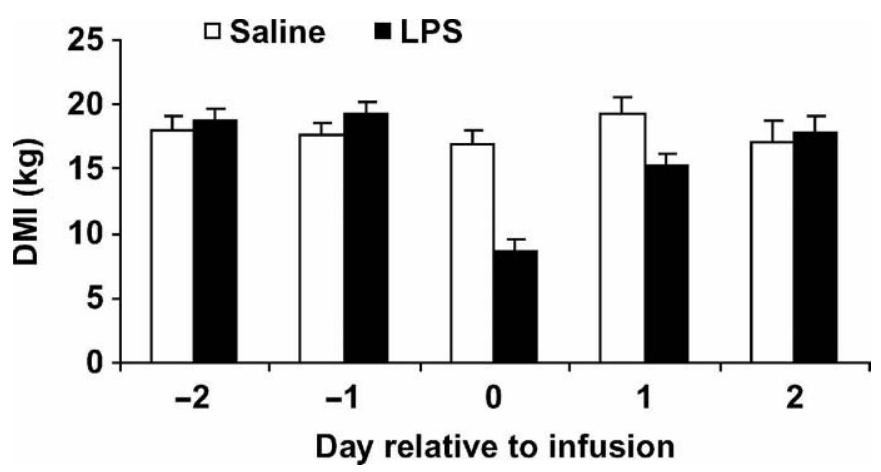

Figure 4. Daily feed DMI each day relative to the infusion of intramammary LPS or saline into dairy cows during early lactation. Error bars represent the standard error of the mean for daily intake. **Treatment by time effect, $P<0.01$.

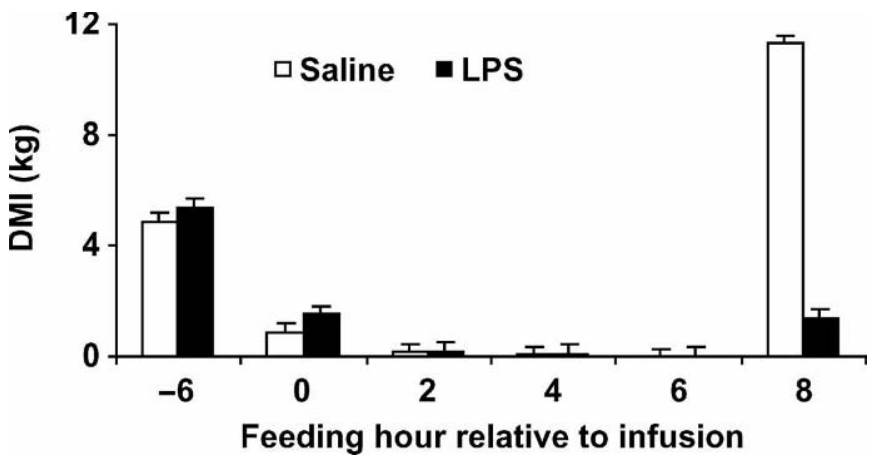

Figure 5. Infusion day feed DMI in the hours relative to the infusion of intramammary LPS or saline into dairy cows during early lactation. Error bars represent the standard error of the mean at each time point. ${ }^{*} *$ Treatment by time effect, $P<0.01$.

from control cows at $20 \mathrm{~h}$ (Figure 6 ; treatment by time effect, $P<0.01)$. Heart rate showed a similar pattern to rectal temperature following LPS infusion, increasing by about $29 \%$ over saline-treated control cows; however, heart rate of LPS-infused cows remained moderately elevated ( $11 \%$ greater) even at $44 \mathrm{~h}$ after treatment (treatment by time effect, $P<0.01$; data not shown). Plasma cortisol concentration was increased in LPS-infused cows by $90 \mathrm{~min}$ and remained elevated at least 6 -fold above that of control cows for the duration of the experimental period (Figure 7 treatment $\times$ time effect, $P<0.01)$. Additionally, plasma TNF- $\alpha$ concentration was increased $>10$-fold in LPS-infused cows only (data not shown).

Plasma glucose enrichment with D2-glucose following a primed continuous infusion of D2-glucose is shown in Figure 8. A peak in enrichment $(\sim 3$ mole percent excess) is evident $2 \mathrm{~min}$ after the $14-\mu \mathrm{mol} / \mathrm{kg}$ of bolus infusion of D2-glucose. Enrichment following this peak rapidly declined to about $0.80 \mathrm{MPE}$ until $-210 \mathrm{~min}$

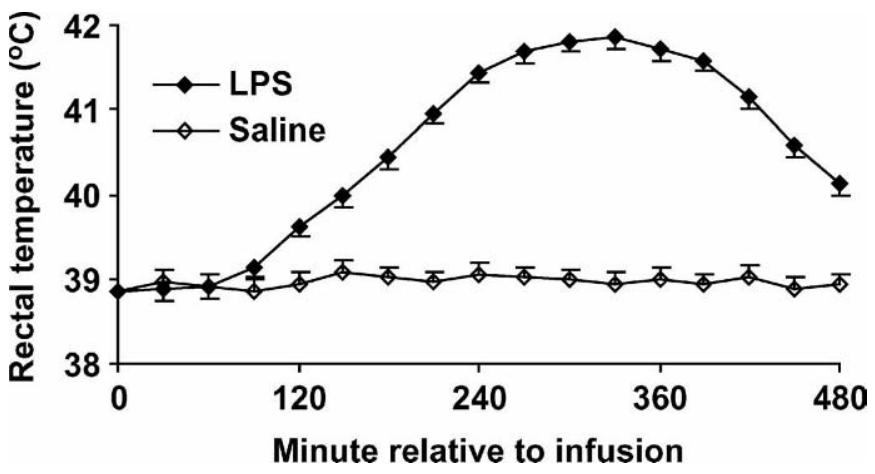

Figure 6. Rectal temperature following the infusion of intramammary LPS or saline into dairy cows during early lactation. Error bars represent the standard error of the mean at each time point. **Treatment by time effect, $P<0.01$. 


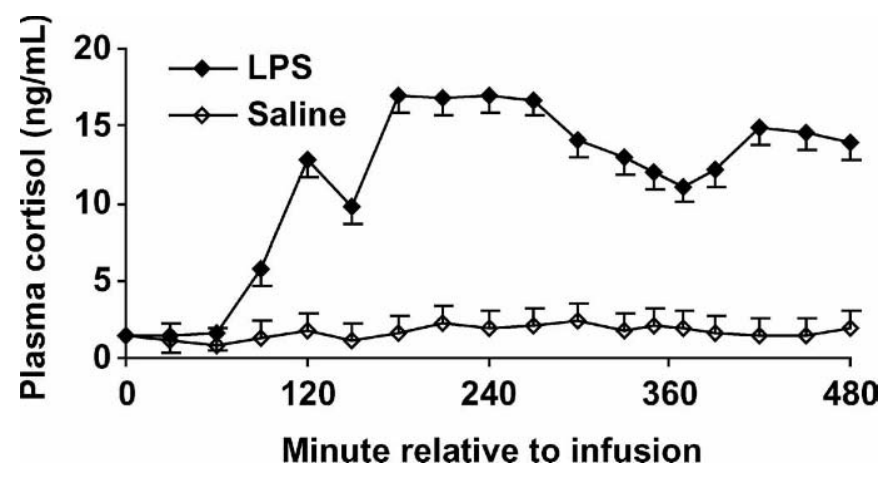

Figure 7. Plasma cortisol concentration following intramammary LPS or saline infusion into early lactation dairy cows. Means were adjusted by analysis of covariance using the mean cortisol concentration for each treatment group from -240 through 0 min relative to intramammary infusion. Error bars represent the standard error of the mean at each time point. ${ }^{*} *$ Treatment by time effect, $P<0.01$.

when the $11.5-\mu \mathrm{mol} /(\mathrm{kg} \times \mathrm{h})$ continuous infusion was initiated. Neither peak nor washout curve enrichment were different in cows subsequently receiving either the LPS or saline treatments $(P>0.20)$. Plasma glucose enrichment reached a plateau at -90 min because enrichment within treatment did not change with time from -90 through $0 \mathrm{~min}$. Significant separation of the enrichment curves for cows on each treatment is evident especially from 120 through 390 min (Figure 8). Figure 9 depicts enrichment during the treatment period after covariate adjustment of the enrichment values to account for pretreatment ( -90 through $0 \mathrm{~min}$ ) variation. Lipopolysaccharide-infused cows displayed lower glucose enrichment through 390 min (treatment by time effect, $P<0.01)$. Importantly, LPS-treated cows experienced a posttreatment period of isotopic steady

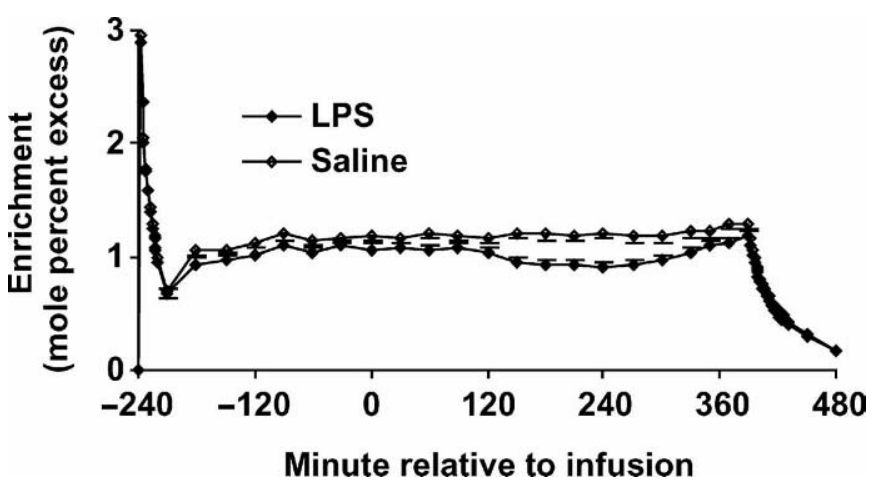

Figure 8. Plasma glucose enrichment with 6,6-deuterated-glucose (D2-glucose) following a primed continuous infusion of D2-glucose into early lactation dairy cows administered intramammary LPS or saline. This figure is shown to depict overall enrichment pattern. Relevant statistics are detailed in subsequent figures.

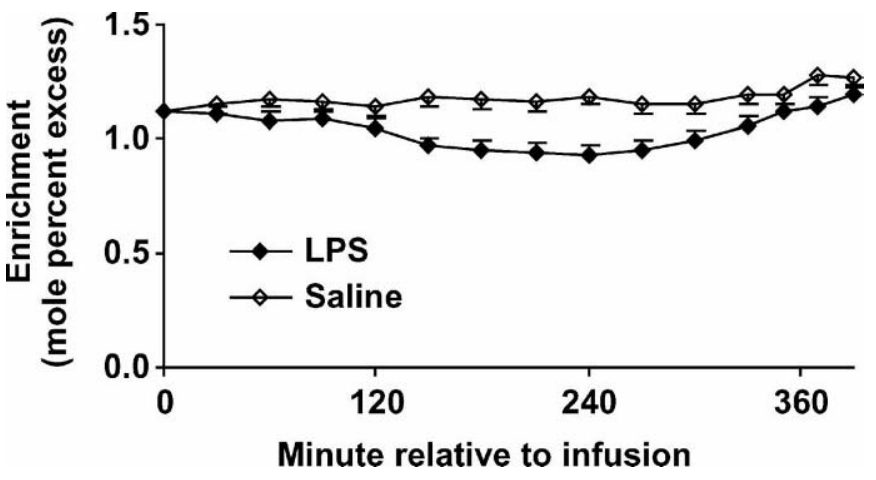

Figure 9. Plasma glucose enrichment with 6,6-deuterated-glucose (D2-glucose) following a primed continuous infusion of D2-glucose into early lactation dairy cows administered intramammary LPS or saline at $0 \mathrm{~min}$. Data were covariately adjusted using the mean plateau enrichment from -90 through 0 min. Error bars represent the standard error of the mean at each timepoint. **Treatment by time effect, $P<0.01$.

state from 150 through $270 \mathrm{~min}$ (treatment by time effect within treatment, $P>0.20$ ).

Plasma kinetic variables calculated from the enrichment washout curve following the D2-glucose bolus are reported in Table 2. Consistent with the similarity in the enrichment curves for cows assigned to each treatment, there were no treatment differences in glucose pool size (263 $\pm 7 \mathrm{mmol})$, glucose elimination rate constant $\left(0.0514 \pm 0.001 \mathrm{~min}^{-1}\right)$, half-life $(13.5 \pm 0.3 \mathrm{~min})$, turnover time $(19.5 \pm 0.4 \mathrm{~min})$, or $\mathrm{Ra}(810 \pm 26 \mathrm{mmol} /$ h). Calculation of rate of appearance using data from the enrichment washout curve resulted in greater values $(P<0.01)$ than when glucose $\mathrm{Ra}$ was calculated from the plateau enrichment at isotopic steady state ( $810 \pm 26$ vs. $689 \pm 33 \mathrm{mmol} / \mathrm{h}$; Table 2$)$.

Plasma glucose Ra during the pretreatment isotopic steady-state period was not different between cows assigned to the LPS or saline treatments (treatment by time effect, $P>0.20$ ); however, the mean of these values ( -90 through $0 \mathrm{~min}$ ) for each cow added to the statistical model as a covariate was significant $(P<0.01)$. Covari-

Table 2. Pretreatment glucose kinetic variables from cows assigned to intramammary LPS or saline infusion treatments

\begin{tabular}{lllll}
\hline Kinetic variable & LPS & Saline & SEM & $P$ \\
\hline $\begin{array}{l}\text { Pool size, mmol } \\
\text { Elimination rate constant }\end{array}$ & 266 & 259 & 7 & 0.49 \\
$\begin{array}{l}\text { (k), min } \\
\text { Glucose half-life, min }\end{array}$ & 0.0517 & 0.0511 & 0.0010 & 0.71 \\
$\begin{array}{l}\text { Glucose turnover time, min } \\
\mathrm{Ra}^{1} \text { from washout curve, }\end{array}$ & 13.45 & 13.61 & 0.26 & 0.66 \\
$\quad \mathrm{mmol} / \mathrm{h}$. & 825 & 79.63 & 0.38 & 0.67 \\
$\begin{array}{l}\text { Ra from isotopic steady } \\
\text { state, mmol/h }\end{array}$ & 715 & 662 & 26 & 0.41 \\
\hline
\end{tabular}

${ }^{1} \mathrm{Ra}=$ Rate of appearance. 


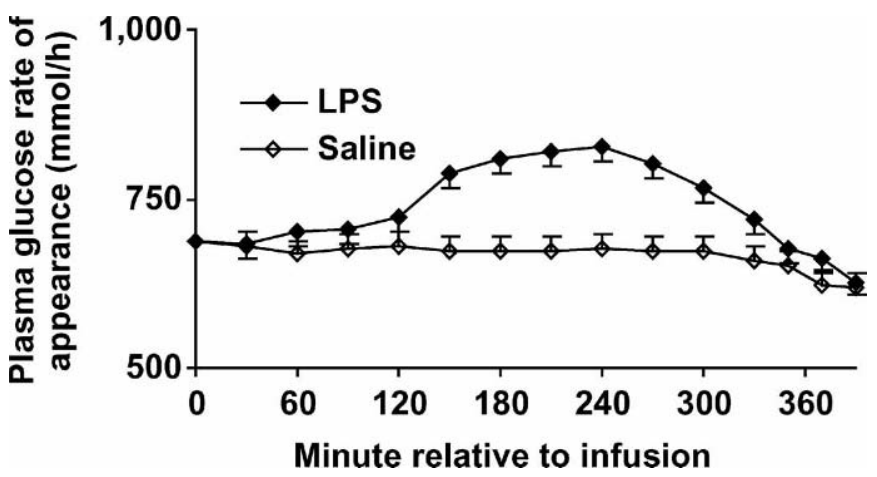

Figure 10. Plasma glucose rate of appearance determined after plateau enrichment of plasma glucose with deuterated glucose into early lactation dairy cows administered intramammary LPS or saline at $0 \mathrm{~min}$. Data were covariately adjusted using the mean rate of appearance during the steady-state period from -90 through 0 mins. Error bars represent the standard error of the mean at each time point. **Treatment by time effect, $P<0.01$.

ately adjusted $\mathrm{Ra}$ values for the treatment period are shown in Figure 10. The Ra calculated during the posttreatment period of isotopic steady state (150 through $270 \mathrm{~min}$ ) was greater for LPS-treated cows than for saline-treated cows (treatment by time effect, $P<0.01$ ). The difference in glucose appearance, calculated from the difference in area between the curves for the posttreatment period from 0 through 390 was $0.48 \mathrm{~mol}$ or $87 \mathrm{~g}$ between treatments.

Plasma metabolite and hormone concentrations during the posttreatment period are shown in Figures 11 through 15. Plasma glucose concentrations (Figure 11) were relatively stable; however, there was a statistically significant treatment by time effect $(P<0.01)$ for this variable. Evaluation of multiple comparisons (pdiff

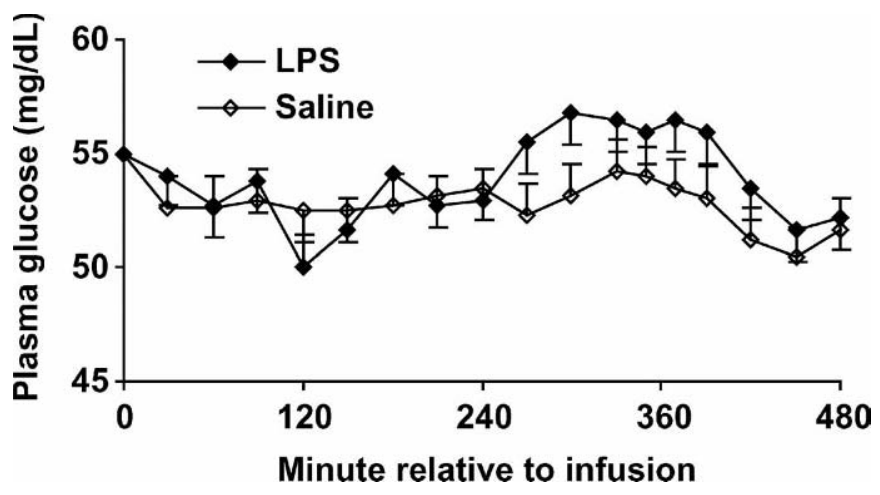

Figure 11. Plasma glucose concentration following intramammary LPS or saline infusion into early lactation dairy cows. Means were adjusted by analysis of covariance using the mean glucose concentration for each treatment group from -240 through 0 min relative to intramammary infusion. Error bars represent the standard error of the mean at each time point. ${ }^{*}$ *Treatment by time effect, $P<0.01$.

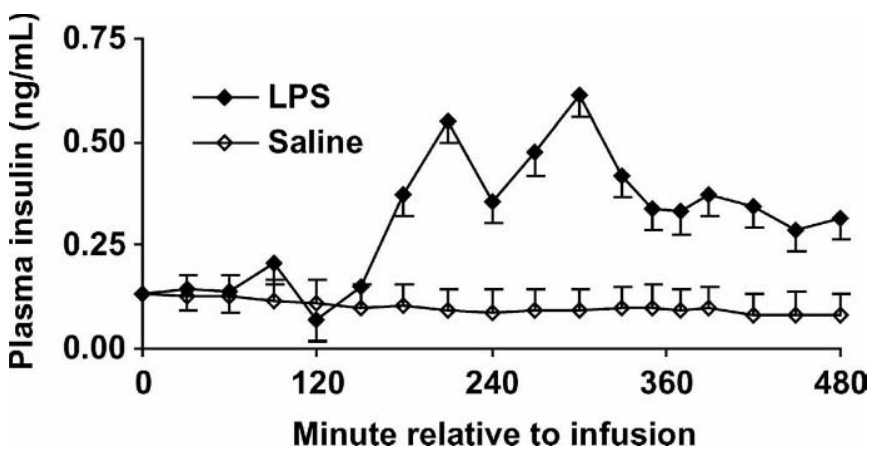

Figure 12. Plasma insulin concentration following intramammary LPS or saline infusion into early lactation dairy cows. Means were adjusted by analysis of covariance using the mean insulin concentration for each treatment group from -240 through 0 min relative to intramammary infusion. Error bars represent the standard error of the mean at each time point. **Treatment by time effect, $P<0.01$.

option of SAS) at individual time points suggested that the significant overall treatment by time effect on plasma glucose concentration was the result of a small increase in plasma glucose concentration of LPS-infused cows beginning at $270 \mathrm{~min}$. Interestingly, plasma insulin concentration (Figure 12) increased dramatically at $180 \mathrm{~min}$ and remained elevated at 200 to $300 \%$ of saline-infused controls through $480 \mathrm{~min}$ (treatment by time effect, $P<0.01$ ). In contrast, plasma NEFA concentration of LPS-infused cows remained constant at approximately $500 \mu \mathrm{Eq} / \mathrm{L}$ throughout the posttreatment period, whereas the NEFA concentration of saline-treated cows more than doubled (Figure 13; treatment by time effect, $P<0.01$ ). Plasma glycerol (Figure 14) and BHBA concentrations (Figure 15) followed a similar, although less exaggerated pattern as plasma NEFA in that LPS administration resulted in decreased

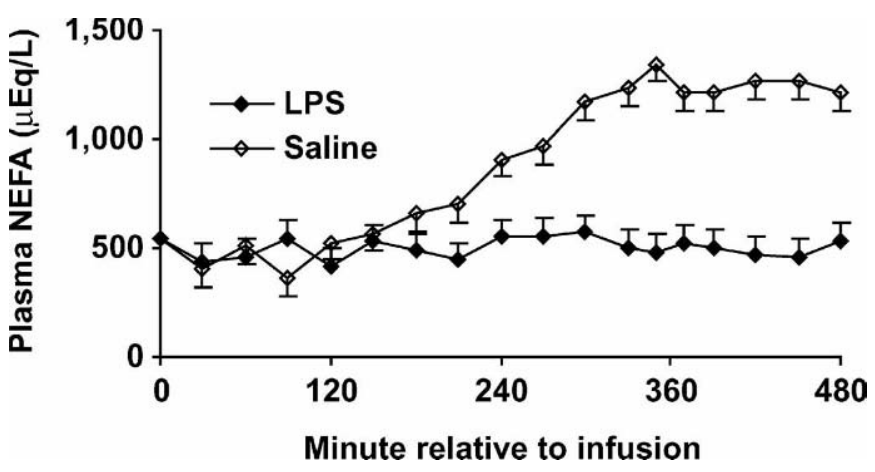

Figure 13. Plasma NEFA concentration following intramammary LPS or saline infusion into early lactation dairy cows. Means were adjusted by analysis of covariance using the mean NEFA concentration for each treatment group from -240 through 0 min relative to intramammary infusion. Error bars represent the standard error of the mean at each time point. **Treatment by time effect, $P<0.01$. 


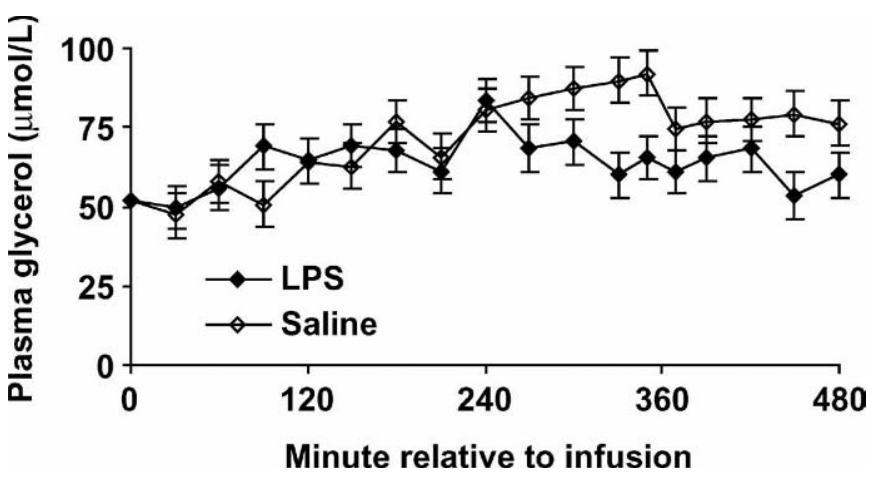

Figure 14. Plasma glycerol concentration following intramammary LPS or saline infusion into early lactation dairy cows. Means were adjusted by analysis of covariance using the mean glycerol concentration for each treatment group from -240 through 0 min relative to intramammary infusion. Error bars represent the standard error of the mean at each time point. **Treatment by time effect, $P=0.02$.

concentrations relative to those in control cows. Plasma glycerol concentration of saline-infused cows increased (treatment by time effect, $P=0.02$ ) by up to $40 \%$ relative to concentrations in LPS-infused cows from 270 through $480 \mathrm{~min}$ after intramammary infusion. Plasma BHBA concentration of LPS-infused cows slowly declined by a maximum of $37 \%$ at $450 \mathrm{~min}$, whereas that of saline-infused cows slowly increased by about $14 \%$ during the posttreatment period through $480 \mathrm{~min}$ (treatment by time effect, $P<0.01$ ).

\section{DISCUSSION}

The results of feed analysis indicate that both the prepartum and postpartum diets were in accordance with recommendations of the NRC (2001) and CNCPS

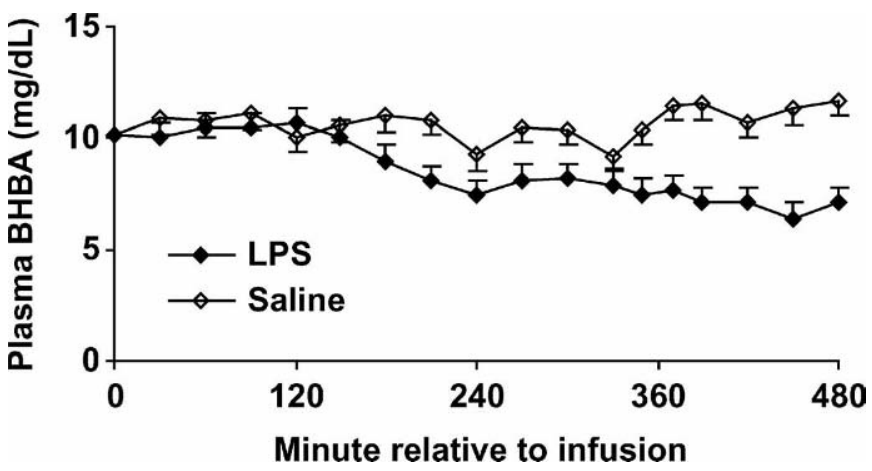

Figure 15. Plasma BHBA concentration following intramammary LPS or saline infusion into early lactation dairy cows. Means were adjusted by analysis of covariance using the mean BHBA concentration for each treatment group from -240 through 0 min relative to intramammary infusion. Error bars represent the standard error of the mean at each time point. **Treatment by time effect, $P<0.01$.
(Fox et al., 2004) for cows during the peripartum period. The observed mean DMI prior to intramammary infusion was predicted by CNCPS to afford $28.1 \mathrm{~kg}$ of metabolizable protein-allowable milk production/d and $29 \mathrm{~kg}$ of ME-allowable milk production/d. The actual daily production of $37 \mathrm{~kg}$ of milk meant that these cows in early lactation were experiencing a deficit of both metabolizable protein and $\mathrm{ME}$ and were predicted to lose 1 unit of BCS (1- to 5-point scale; Edmonson et al., 1989) in $71 \mathrm{~d}$ (CNCPS; Fox et al., 2004). The measured change in BCS over time in this study (data not shown) is consistent with this prediction.

Increased plasma cortisol, mammary quarter-specific SCC, rectal temperature and heart rate (data not shown); decreased infusion day and daily DMI; and milk production and changes in milk composition (data not shown) all confirm the presence of a vigorous immune response to LPS. Conversely, the complete absence of perturbations in any of these variables yielded confidence that an effective control treatment by the intramammary infusion of saline was established in this study.

Intramammary LPS infusion decreased milk yield and altered milk components as previously observed (Shuster et al., 1991). Shuster et al. (1991) reported that despite a lack of inflammation in noninfused quarters, milk production was decreased in all quarters following endotoxin infusion into 2 homolateral quarters. Although those researchers observed a more severe and prolonged suppression in infused quarters, they concluded that mastitic hypogalactia is mediated by multiple pathophysiological events and is not solely due to inflammatory damage in the mammary epithelium. They additionally speculated that a portion of the reduced lactational performance may result from escape of milk components from the udder into the circulation (Shuster et al., 1991). The exact mechanisms responsible for these changes have not been fully elucidated, but are likely the result of multiple local and systemic factors probably affected by the production of cytokines by leukocytes within the mammary gland (Shuster and Harmon, 1992; Shuster et al., 1995).

Whole-udder milk from all mammary quarters showed an identical pattern of milk SCC (data not shown) as did udder-half milk (Figure 3) following LPS infusion. The udder-half data are reported for 2 reasons. First, these data confirm that inflammation occurred only in the right (LPS-infused) quarters of LPS-treated cows. Second, these data confirm that inflammation or infection did not occur in the infused (right) quarters of control animals after the external barrier of the mammary gland had been breached by administration of treatments. This confirmation was central to our ability to compare LPS-infused cows to saline-infused cows 
because any treatment-induced inflammation in control animals would have confounded results from this study.

The effects of LPS on DMI were typical of the effects of the LPS-induced proinflammatory cytokine response observed in several species (Johnson, 1998) that may be even more significant for periparturient dairy cows already in negative energy balance (Ingvartsen and Andersen, 2000). This decrease in feed intake requires that the effects of feed intake be controlled (pair-fed controls) during experiments involving the interactions of inflammation and metabolism such that the metabolic effects of inflammation can be separated from those of decreased feed intake. In ruminants, the route of administration of LPS has an additive effect on nutrition greater than changes in feed intake alone. Lohuis et al. (1988) reported that intravenously infused LPS, but not intramammary infusion of LPS, resulted in decreased rumen motility that could decrease nutrient absorptive capacity to a greater extent than the decrease in feed intake would indicate. In the current study, control cows were pair-fed with an individual LPS-infused cow during the first $8 \mathrm{~h}$ after intramammary infusion (the period of metabolic study), to avoid the confounding effects of intake. Thus, the metabolic effects reported herein are the direct result of mammary inflammation and not influenced by feeding behavior or digestion kinetics.

A primed continuous infusion of D2-glucose was administered such that the continuous infusion did not begin until 30 min after the initial priming D2-glucose bolus. This design enabled the determination of multiple glucose kinetic variables from the D2-glucose washout curve (during the first $30 \mathrm{~min}$ ) that could not have been determined by plateau enrichment alone (Wolfe, 1992). The enrichment washout curves from cows assigned to each treatment were impressively uniform (treatment by time, $P=0.95$ ), and because BW (and therefore dose of D2-glucose bolus administered) were not different between treatments, there were no pretreatment differences in the calculated kinetic variables (Table 2). It is unclear why Ra calculated from the D2-glucose washout curve was higher than Ra calculated from isotopic steady state (Table 2). One explanation for this finding may be that Ra during the washout period was actually higher because of a feeding effect (i.e., increased propionate supply) approximately $2 \mathrm{~h}$ after the morning feeding. Another explanation for the difference in values could be that our assumption that a single-pool model would be sufficient to estimate the kinetic variables might have been flawed (Young, 1977; Judson and Leng, 1972) and might have resulted in a modest overestimation of the subsequent kinetic variables (Shipley and Clark, 1972).
Baird et al. (1983) reported lower glucose turnover rates $(\sim \mathrm{Ra} ; 484 \mathrm{mmol} / \mathrm{h})$ in periparturient lactating cows using radiolabeled glucose than is reported during the pretreatment period in the current study (688 $\mathrm{mmol} / \mathrm{h}$ ). However, average milk weight in the former study was $22.5 \mathrm{~kg} / \mathrm{d}$ compared with $37 \mathrm{~kg} / \mathrm{d}$ in the current study. Similarly, Bauman et al. (1988) reported glucose irreversible loss rates of 503 and $565 \mathrm{mmol} / \mathrm{h}$ for midlactation cows producing 27.5 and $30.7 \mathrm{~kg} / \mathrm{d}$ of milk, respectively. Reynolds et al. (2003) reported a total splanchnic net flux of glucose in catheterized periparturient cows ( $11 \mathrm{~d}$ postpartum) producing $38 \mathrm{~kg}$ of $\mathrm{milk} / \mathrm{d}$ to be $631 \mathrm{mmol} / \mathrm{h}$. These results in contemporary cows are very consistent with those in the current study, especially when estimated renal glucose production is accounted for in addition to the total splanchnic net flux.

Plasma isotopic steady state of D2-glucose enrichment was reestablished during the period from 150 to 270 min after intramammary infusion. Plasma glucose concentration was also relatively stable during this period. The combination of isotopic steady-state and stable plasma glucose concentration indicate that physiologic steady state was achieved; therefore, steady-state kinetics were calculated for this period. Glucose Ra was increased by LPS infusion, but it is unknown whether this increase was due to enhanced glycogenolysis or gluconeogenesis (or some combination thereof). However, periparturient cows have only very low levels of liver glycogen stores that begin to replete at approximately $14 \mathrm{~d}$ after calving (Grummer, 1995). Using a typical liver weight of $8.8 \mathrm{~kg}$ (Reynolds et al., 2004) multiplied by $0.88 \%$ liver wet weight glycogen content in early lactation (Smith, 2004) indicates that a maximum of $77 \mathrm{~g}$ of glycogen could be liberated for glucose release from the periparturient cow liver. An approximation (including the non-steady-state period) of total Ra during the period from 0 through 390 min indicated that about $87 \mathrm{~g}$ more glucose appeared in the plasma of cows infused with LPS than with saline. Further evidence that the increased hepatic glucose release was due mostly to gluconeogenesis and not glycogenolysis comes from the comparison of the LPS-infused cows with the saline-infused cows. The saline-infused cows were in greater negative energy balance than were the LPS-infused cows because, although they were pair-fed with the LPS-infused cows, milk production was not suppressed in these animals. Therefore, the control cows would likely have mobilized any available hepatic glycogen stores during the experimental period to support lactation, yet the LPS-treated cows still had a greater plasma glucose Ra. Increased glucose $\mathrm{Ra}$ from gluconeogenesis is also consistent with the tendency for increased in vitro capacity of liver slices to convert 
propionate into glucose following increasing doses of LPS into midlactation cows (Waldron et al., 2003).

Calculations (NRC, 2001) of energy demand for the experimental period indicate that 14.6 and $31.0 \mathrm{Mcal}$ of $\mathrm{ME}$ were used for milk synthesis and 9.0 and 8.9 Mcal of ME were used for maintenance during the 14$\mathrm{h}$ experimental period for the LPS- and saline-infused cows, respectively. Furthermore, Klasing (1988) reported that maintenance requirements were increased by 10 to $15 \%$ for each degree Celsius of fever. The rectal temperature of LPS-infused cows was increased by a mean of $0.76^{\circ} \mathrm{C}$ over the entire 14-h experimental period, resulting in an adjusted approximate maintenance requirement of $10.1 \mathrm{Mcal}$. The calculated total ME required for milk synthesis and maintenance during the 14-h experimental period was 24.6 and 40.0 Mcal for the LPS- and saline-infused cows, respectively. Alternatively, the 585-g difference in milk lactose yield between LPS- and saline-infused cows resulted in $760 \mathrm{~g}$ less glucose required by the mammary gland of the LPSinfused cows (NRC, 2001). Including the $87 \mathrm{~g}$ of glucose from the higher glucose Ra of LPS-infused cows indicates that $847 \mathrm{~g}$ more glucose were available for these animals to use for metabolic purposes. The fate of this extra glucose (or energy) is unknown; however, Naylor and Kronfeld (1985) reported that up to $55 \%$ of the glucose released from the liver of endotoxic sheep could be accounted for by the recycling of lactate in the Cori cycle; therefore, it is possible that much of the glucose released from the liver following LPS infusion did not represent "new" net glucose production.

Another interesting finding in the current study was that glucose $\mathrm{Ra}$ was increased following LPS infusion despite a dramatically increased plasma insulin concentration. In sheep, Weekes et al. (1983) reported decreased glucose rate of appearance with increasing amounts of insulin infusion, and Brockman (1990) reported that insulin infusion decreased hepatic glucose release caused by decreased hepatic extraction of gluconeogenic precursors other than propionate; propionate incorporation into glucose was minimally affected. She et al. (1999) suggested that elevated counter-regulatory plasma insulin concentration decreased phosphoenolpyruvate carboxykinase expression (a rate-limiting enzyme of gluconeogenesis) despite exogenous glucagon secretion, confirming the role of insulin in the downregulation of hepatic gluconeogenesis in the dairy cow under non-inflammatory conditions. Hyperinsulinemia (and hyperglucagonemia) occurs in many non-ruminant species following LPS infusion (Klasing, 1988); however, these species also usually experience a period of decreased gluconeogenesis. The only other report of glucose entry during inflammation in ruminants occurred in sheep. Naylor and Kronfeld (1985) reported that in- travenous LPS administration into hepatically catheterized ewes dramatically increased plasma insulin concentration and also resulted in a biphasic incidence of increased hepatic glucose release. Those researchers attributed the initial glucose release (through $180 \mathrm{~min}$ ) to increased glycogenolysis and attributed the second phase of glucose release to enhanced gluconeogenesis. The mechanism of enhanced glucose appearance requires further study. Furthermore, the reason for the increased plasma insulin concentration prior to an increase in plasma glucose concentration also requires further study.

Despite the increased plasma insulin concentration, plasma glucose concentration increased subtly following LPS infusion. Therefore, not only was glucose production unexpectedly increased, insulin-dependent glucose utilization may also have been attenuated, as at first glance, we would have expected a reduction in plasma glucose concentrations with the marked increase in plasma insulin. Kushibiki et al. (2001) reported that sustained administration of recombinant bovine TNF- $\alpha$ induced insulin resistance in steers, and Ohtsuka et al. (2001) reported that insulin resistance was correlated with serum TNF- $\alpha$ activity in dairy cows with fatty liver. Furthermore, TNF- $\alpha$ and other proinflammatory cytokines are also reported to induce insulin resistance in other species (Xaio et al., 2001; Ling et al., 1994). Despite these arguments, it is unclear whether the cows in the current study experienced peripheral insulin resistance. As noted, the combination of increased plasma glucose $\mathrm{Ra}$ and decreased glucose utilization by the mammary gland resulted in approximately $847 \mathrm{~g}(4,706 \mathrm{mmol})$ of additional glucose for nonmammary disposal over the 14-h experimental period. Over $14 \mathrm{~h}, 4,706 \mathrm{mmol}$ of glucose is equal to 336 $\mathrm{mmol}$ of glucose to be disposed/h, an amount (on an hourly basis) approximately $125 \%$ of the total glucose pool size estimated from the D2-glucose washout curve (266 mmol; Table 2). Brockman (1983) and Weekes et al. (1983) reported that a plasma insulin increment of approximately $3.7 \mathrm{ng} / \mathrm{mL}$ doubled the glucose clearance rate in sheep. Comparatively, the mean plasma insulin increment after LPS was only approximately $0.30 \mathrm{ng} /$ $\mathrm{mL}$ in the current study, suggesting that increased nonmammary glucose disposal occurred despite relatively moderately increased plasma insulin concentrations. Clearly, nonmammary glucose uptake was increased by LPS administration in the current study; however, it is not known to what degree this increased glucose disposal was insulin- or non-insulin dependent. Lang (1995) reported that the increased glucose utilization following LPS administration in rats was a result of non-insulin-dependent glucose uptake. 
Plasma concentrations of NEFA remained static following LPS infusion, despite minimal feed intake after LPS infusion. The mechanism responsible for the lower plasma NEFA during a period of minimal feed intake and the likely increases in the lipolytic hormones epinephrine and cortisol are unclear. Certainly, the increased levels of circulating insulin may be involved; however, this remains to be confirmed, especially considering the ineffectiveness of insulin to promote other normal mechanistic responses. Proinflammatory cytokines reportedly alter lipid metabolism in a tissue-specific manner in other species (Feingold and Grunfeld, 1987); however, administration of recombinant bovine TNF- $\alpha$ resulted in increased (not decreased) plasma NEFA concentration in lactating dairy cows (Kushibiki et al., 2003) and in dairy heifers (Kushibiki et al., 2002). As calculated previously, the approximate total ME required for milk synthesis and maintenance during the 14-h experimental period was 24.6 and $40.0 \mathrm{Mcal}$ for the LPS- and saline-infused cows, respectively. Although energy requirements were significantly reduced following LPS administration, the almost complete anorexia of LPS-infused cows during the experimental period would still result in negative energy balance if calculated for this acute timeframe. However, ruminal digestion from the pretreatment alimentation was likely still active during the experimental period and, unlike intravenous LPS administration, intramammary LPS infusion has been reported to not attenuate gut motility in ruminants (Lohuis et al., 1988). Therefore, it is likely that significant nutrients were absorbed during the period of anorexia; thus, whole-animal energy status is unknown. Although it is tempting to speculate that plasma NEFA concentrations are a reflection of wholeanimal energy status, the unique endocrine and inflammatory milieu following LPS administration may complicate this interpretation.

The decreased plasma glycerol concentration following LPS infusion is consistent with the decreased plasma NEFA concentration. The origin of a significant proportion of the glycerol released into plasma is from lipolysis in adipose tissue as triglycerides are cleaved into 3 fatty acid molecules (NEFA) and one glycerol molecule. The decreased plasma glycerol concentration of LPS-infused cows suggests that less glycerol was released from adipose tissue; therefore, lipolysis might have been decreased following LPS infusion. Although the NEFA can either be directly reincorporated into triglycerides by reesterification to a different glycerol molecule or can be released into the blood in the form of NEFA, very little of the glycerol that is liberated from triglycerides can be directly reused in adipose tissue and must therefore be released into the blood (Shirley et al., 1973). Therefore, glycerol entry into blood has been used as a proxy to quantify lipolysis. Furthermore, comparison of glycerol entry with NEFA entry into plasma has been used as a proxy for the amount of reesterification of NEFA in adipose tissue (Dunshea et al., 1990). However, neither NEFA nor glycerol entry rates into plasma were directly measured in the current study, making a potential discussion of lipolysis vs. reesterification following LPS administration inappropriate. Dunshea et al. (1990) reported that although plasma NEFA concentration was highly correlated with NEFA entry rate $(r=0.96)$, plasma glycerol concentration was only moderately correlated with glycerol entry rate $(\mathrm{r}=0.55)$.

Similar to plasma NEFA, plasma BHBA concentration in LPS-infused cows was also lower than in control cows. Steiger et al. (1999) reported decreased BHBA in dairy heifers, and Naylor and Kronfeld (1985) reported decreased BHBA and acetoacetate in ewes; however, although these studies included either pair-fed or feeddeprived animals, LPS was administered intravenously and, therefore, might have affected rumen motility (Lohuis et al., 1988) and perhaps rumen metabolism (including alimentary ketogenesis by the rumen epithelium). Hepatic ketogenesis is decreased by LPS (Kaminski et al., 1979) and some proinflammatory cytokines (Memon et al., 1992) in laboratory animals; however, further investigation of ketogenesis in ruminants is warranted to determine whether lower circulating BHBA is driven simply by supply-related issues or more mechanistic changes in metabolic pathways responsible for ketone body production.

\section{CONCLUSIONS}

Curtis et al. (1985) reported a relationship whereby dairy cows that experienced either metabolic disorders or mastitis during early lactation had a $>9$-fold risk of developing the other adverse health event. Much research has focused on how metabolic factors characteristic of early lactation and negative energy balance affect immunity, but very little research has targeted the effects of infection or inflammation on specific mechanisms that may be the cause of development of metabolic disease. We hypothesized that experimental mastitis would result in quantitative changes in energy metabolism that would predispose the periparturient cow to the development of the fatty liver-ketosis complex; however, our results indicate that, at least during LPS-induced experimental mastitis, glucose production and plasma glucose concentration are increased, and plasma NEFA and BHBA are decreased. These results represent only the very early stages of inflammation and that the metabolic effects of sustained inflammation merit further study. However, these results are not 
consistent with a causal relationship between mastitis and energy-related metabolic disorders and instead suggest a coordinated protective effect by the immune system on metabolism during the early stages of mammary insult.

\section{REFERENCES}

AOAC. 2000. Official Methods of Analysis of the Association of Official Analytical Chemists, International. 17th Ed. Assoc. Off. Anal. Chem., Arlington, VA.

Baird, G. D., J. G. Van Der Walt, and E. N. Bergman. 1983. Wholebody metabolism of glucose and lactate in productive sheep and cows. Br. J. Nutr. 50:249-265.

Bauman, D. E., C. J. Peel, W. D. Steinhour, P. J. Reynolds, H. F. Tyrrell, A. C. Brown, and G. L. Haaland. 1988. Effect of bovine somatotropin on metabolism of lactating dairy cows: Influence on rates of irreversible loss and oxidation of glucose and nonesterified fatty acids. J. Nutr. 118:1031-1040.

Boobis, L. H., and R. J. Maughan. 1983. A simple one-step enzymatic fluorometric method for the determination of glycerol in 20 microliters of plasma. Clin. Chim. Acta 132:173-179.

Brockman, R. P. 1983. Effects of insulin and glucose on the production of glucose in sheep (Ovis aries). Comp. Biochem. Physiol. A 74:681-685.

Brockman, R. P. 1990. Effect of insulin on the utilization of propionate in gluconeogenesis in sheep. Br. J. Nutr. 64:95-101.

Curtis, C. R, H. N. Erb, C. J. Sniffen, R. D. Smith, and D. S. Kronfeld. 1985. Path analysis of dry period nutrition, postpartum metabolic and reproductive disorders, and mastitis in Holstein cows. J. Dairy Sci. 68:2347-2360.

Dunshea, F. R., A. W. Bell, and T. E. Trigg. 1990. Non-esterified fatty acid and glycerol kinetics and fatty acid re-esterification in goats during early lactation. Br. J. Nutr. 64:133-145.

Edmonson, A. J., I. J. Lean, L. D. Weaver, T. Farver, and G. Webster. 1989. A body condition scoring chart for Holstein dairy cows. J. Dairy Sci.72:68-78.

Feingold, K. R., and C. Grunfeld. 1987. Tumor necrosis factor-alpha stimulates hepatic lipogenesis in the rat in vivo. J. Clin. Invest. $80: 184-190$

Fox, D. G., L. O. Tedeschi, T. P. Tylutki, J. B. Russell, M. E. Van Amburgh, L. E. Chase, A. N. Pell, and T. R. Overton. 2004. The Cornell Net Carbohydrate and Protein System for evaluating herd nutrition and nutrient excretion. Anim. Feed Sci. Technol. 112:29-78.

Grohn, Y. T., S. W. Eicker, V. Ducrocq, and J. A. Hertl. 1998. Effect of diseases on the culling of Holstein dairy cows in New York State. J. Dairy Sci. 81:966-978.

Grommers, F. J., D. Van De Geer, H. Van Der Vliet, P. A. J. Henricks, and F. P. Nijkamp. 1989. Polymorphonuclear leukocyte function: relationship between induced migration into the bovine mammary gland and in vitro cell activity. Vet. Immunol. Immunopathol. 23:75-83.

Grummer, R. R. 1995. Impact of changes in organic nutrient metabolism on feeding the transition dairy cow. J. Dairy Sci. 73:28202833.

Ingvartsen, K. L., and J. B. Andersen. 2000. Integration of metabolism and intake regulation: A review focusing on periparturient animals. J. Dairy Sci. 83:1573-1597.

Johnson, R. W. 1998. Immune and endocrine regulation of food intake in sick animals. Domest. Anim. Endocrinol. 15:309-319.

Judson, G. J., and R. A. Leng. 1972. Estimation of the total entry rate and resynthesis of glucose in sheep using glucoses uniformly labelled with ${ }^{14} \mathrm{C}$ and variously labelled with ${ }^{3} \mathrm{H}$. Aust. J. Biol. Sci. 25:1313-1332.

Kaminski, Jr., M. V., H. A. Neufeld, and J. G. Pace. 1979. Effect of inflammatory and noninflammatory stress on plasma ketone bodies and free fatty acids and on glucagon and insulin in peripheral and portal blood. Inflammation 3:289-294.
Klasing, K. C. 1988. Nutritional aspects of leukocytic cytokines. J. Nutr. 118:1436-1446.

Kushibiki, S., K. Hodate, H. Shingu, T. Hayashi, E. Touno, M. Shinoda, and Yokomizo. 2002. Alterations in lipid metabolism induced by recombinant tumor necrosis factor-alpha administration into dairy heifers. J. Anim. Sci. 80:2151-2157.

Kushibiki, S., K. Hodate, H. Shingu, Y. Obara, E. Touno, M. Shinoda, and Y. Yokomizo. 2003. Metabolic and lactational responses during recombinant bovine tumor necrosis factor- $\alpha$ treatment in lactating cows. J. Dairy Sci. 86:819-827.

Kushibiki, S., K. Hodate, H. Shingu, Y. Ueda, Y. Mori, T. Itoh, and Y. Yokomizo. 2001. Effects of long-term administration of recombinant bovine tumor necrosis factor- $\alpha$ on glucose metabolism and growth hormone secretion in steers. Am. J. Vet. Res. 62:794-798.

Lacetera, N., D. Scalia, U. Bernabucci, B. Ronchi, D. Pirazzi, and A. Nardone. 2005. Lymphocyte functions in overconditioned cows around parturition. J. Dairy Sci. 88:2010-2016.

Lang, C. H. 1995. Neural regulation of the enhanced uptake of glucose in skeletal muscle after endotoxin. Am. J. Physiol. 269:R437$\mathrm{R} 444$

Ling, P. R., B. R. Bistrian, B. Mendez, and N. W. Istfan. 1994. Effects of systemic infusions of endotoxin, tumor necrosis factor, and interleukin-1 on glucose metabolism in the rat: Relationship to endogenous glucose production and peripheral tissue glucose uptake. Metabolism 43:279-284.

Littell, R. C., P. R. Henry, and C. B. Ammerman. 1998. Statistical analysis of repeated measures data using SAS procedures. J. Anim. Sci. 76:1216-1231.

Lohuis, J. A. C. M., J. H. M. Verheijden, C. Burvenich, and A. S. J. P. A. M. van Miert. 1988. Pathophysiological effects of endotoxins in ruminants. Vet. Q. 10:117-125.

Mallard, B. A., J. C. Dekkers, M. J. Ireland, K. E. Leslie, S. Sharif C. Lacey Vankampen, L. Wagter, and B. N. Wilkie. 1998. Alteration in immune responsiveness during the periparturient period and its ramification on dairy cow and calf health. J. Dairy Sci. 81:585-595.

Memon, R. A., K. R. Feingold, A. H. Moser, W. Doerrler, S. Adi, C. A. Dinarello, and C. Grunfeld. 1992. Differential effects of interleukin-1 and tumor necrosis factor on ketogenesis. Am. J. Physiol. 263:E301-E309.

Naylor, J. M., and D. S. Kronfeld. 1985. In vivo studies of hypoglycemia and lactic acidosis in endotoxic shock. Am. J. Physiol. 248:E309-E316.

NRC. 2001. Nutrient Requirements of Dairy Cattle. 7th rev. ed. Natl. Acad. Press, Washington, DC.

Ohtsuka, H., M. Koiwa, A. Hatsugaya, K. Kudo, F. Hoshi, N. Itoh, H. Yokota, H. Okada, and S. Kawamura. 2001. Relationship between serum TNF activity and insulin resistance in dairy cows affected with naturally occurring fatty liver. J. Vet. Med. Sci. 63:10211025.

Rajala-Schultz, P. J., Y. T. Grohn, C. E. McCulloch, and C. L. Guard. 1999. Effects of clinical mastitis on milk yield in dairy cows. J. Dairy Sci. 82:1213-1220.

Reynolds, C. K., P. C. Aikman, B. Lupoli, D. J. Humphries, and D. E. Beever. 2003. Splanchnic metabolism of dairy cows during the transition from late gestation through early lactation. J. Dairy Sci. 86:1201-1217.

Reynolds, C. K., B. Dürst, B. Lupoli, D. J. Humphries, and D. E. Beever. 2004. Visceral tissue mass and rumen volume in dairy cows during the transition from late gestation to early lactation. J. Dairy Sci. 87:961-971.

SAS User's Guide: Statistics, Version 8 Edition. 2001. SAS Inst. Inc., Cary, NC

Sechen, S. J., F. R. Dunshea, and D. E. Bauman. 1990. Somatotropin in lactating cows: Effect on response to epinephrine and insulin. Am. J. Physiol. 258:E582-588.

She, P., G. L. Lindberg, A. R. Hippen, D. C. Beitz, and J. W. Young. 1999. Regulation of messenger ribonucleic acid expression for gluconeogenic enzymes during glucagon infusions into lactating cows. J. Dairy Sci. 82:1153-1163. 
Shipley, R. A., and R. E. Clark. 1972. Tracer methods for in vivo kinetics: Theory and applications. Acad. Press, Inc., New York, NY.

Shirley, J. E., R. S. Emery, E. M. Convey, and W. D. Oxender. 1973. Enzymic changes in bovine adipose and mammary tissue, serum and mammary tissue hormonal changes with initiation of lactation. J. Dairy Sci. 56:569-574.

Shuster D. E., and R. J. Harmon. 1992. High cortisol concentrations and mediation of the hypogalactia during endotoxin-induced mastitis. J. Dairy Sci. 75:739-746.

Shuster, D. E., R. J. Harmon, J. A. Jackson, and R. W. Hemken. 1991. Suppression of milk production during endotoxin-induced mastitis. J. Dairy Sci. 74:3763-3774.

Shuster, D. E., M. E. Kehrli, Jr., and C. R. Baumrucker. 1995. Relationship of inflammatory cytokines, growth hormone, and insulinlike growth factor-I to reduced performance during infectious disease. Proc. Soc. Exp. Biol. Med. 210:140-149.

Shuster, D. E., E. K. Lee, and M. E. Jr., Kehrli. 1996. Bacterial growth, inflammatory cytokine production, and neutrophil recruitment during coliform mastitis in cows within ten days after calving, compared with cows at midlactation. Am. J. Vet. Res. 57:15691575
Smith, K. L. 2004. Effects of prepartum carbohydrate source and chromium supplementation in dairy cows during the periparturient period. M.S. Thesis. Cornell Univ., Ithaca, NY.

Steiger, M., M. Senn, G. Altreuther, D. Werling, F. Sutter, M. Kreuzer, and W. Langhans. 1999. Effect of a prolonged low-dose lipopolysaccharide infusion on feed intake and metabolism in heifers. J. Anim. Sci. 77:2523-2532.

Suriyasathaporn, W., C. Heuer, E. N. Noordhuizen-Stassen, and Y. H. Schukken. 2000. Hyperketonemia and the impairment of udder defense: A review. Vet. Res. 31:397-412.

Waldron, M. R., T. Nishida, B. J. Nonnecke, and T. R. Overton. 2003. Effect of lipopolysaccharide on indices of peripheral and hepatic metabolism in lactating cows. J. Dairy Sci. 86:3447-3459.

Weekes, T. E. C., Y. Sasaki, and T. Tsuda. 1983. Enhanced responsiveness to insulin in sheep exposed to cold. Am. J. Physiol. 244:E335-E345.

Wolfe, R. R. 1992. Radioactive and Stable Isotope Tracers in Biomedicine: Principles and Practice of Kinetic Analysis. Wiley-Liss, Inc. New York, NY.

Xaio, H., W. A. Banks, M. L. Niehoff, and J. E. Morley. 2001. Effect of LPS on the permeability of the blood-brain barrier to insulin. Brain Res. 896:36-42.

Young, J. W. 1977. Gluconeogenesis in cattle: Significance and methodology. J. Dairy Sci. 60:1-15. 